\title{
Philosophiques
}

\section{André Vachet, Marcuse. La révolution radicale et le nouveau socialisme. Essai de synthèse, Éditions de l'Université d'Ottawa, 1986, 229 p., coll. «Sciences sociales», no 11.}

\section{Alain Martineau}

Volume 14, numéro 2, automne 1987

URI : https://id.erudit.org/iderudit/027029ar

DOI : https://doi.org/10.7202/027029ar

Aller au sommaire du numéro

Éditeur(s)

Société de philosophie du Québec

ISSN

0316-2923 (imprimé)

1492-1391 (numérique)

Découvrir la revue

Citer ce compte rendu

Martineau, A. (1987). Compte rendu de [André Vachet, Marcuse. La révolution radicale et le nouveau socialisme. Essai de synthèse, Éditions de l'Université d'Ottawa, 1986, 229 p., coll. «Sciences sociales», no 11.] Philosophiques, 14(2), 455-456. https://doi.org/10.7202/027029ar d'utilisation que vous pouvez consulter en ligne.

https://apropos.erudit.org/fr/usagers/politique-dutilisation/ 
ANDRÉ VACHET, Marcuse : La révolution radicale et le nouveau socialisme. Essai de synthèse, Éditions de l'Université d'Ottawa, 1986, 229 p., coll. «Sciences sociales », $n^{\circ} 11$.

\author{
par Alain Martineau
}

Aussi étrange que cela puisse paraître, ma tâche ici est de rendre compte d'un compte rendu puisque l'auteur nous avertit dans un « avant-propos » qui tient lieu d'introduction qu' "il s'agit essentiellement de rendre compte de l'œuvre de Marcuse prise en elle-même» (p. 18). Un lecteur peut donc s'attendre à l'exposé de la vision marcusienne de la «théorie critique » de l'École de Francfort. Mais il n'en est rien. L'expression n'apparaît même pas dans l'index.

Parlant d'index, remarquons que l'auteur nous offre une « table onomastique » qui ne contient aucun nom propre. Pourtant mon édition du Petit Robert ne rapporte pas d'autre sens au mot onomastique que «ce qui se rapporte aux noms propres »! À la page 228, vous trouverez un renvoi au mot «fouille». J'ai fouillé et je pense qu'il faudrait lire «famille». Le travail des correcteurs n'a pas été très efficace. À titre d'exemple, soulignons l'abus des féminins: une (sic) modèle (p. 64), cette (sic) essai (p. 220); ou l'erreur inverse : un (sic) telle abstraction (p. 77).

Mais revenons à notre propos. Trouverons-nous, par exemple, une critique de l'oeuvre de Marcuse? Vachet entend «reporter toute visée critique » (p. 18).

Son livre comprend deux parties. La première débute dans le style suivant: "La société industrielle avancée se présente à Marcuse comme un tout intégré, une totalité qui en banalise l'extériorité et un système dynamique de fonctions dont le moteur interne est complètement suffisant. » (p. 23) Elle s'intitule "Civilisation et culture répressive" probablement parce que, selon l'auteur, "la pleine compréhension de l'idée de révolution et de ses conséquences exige l'approfondissement des rapports complexes entre la civilisation et la culture » et parce que « aucun des analystes et des critiques de Marcuse ne semble s'être arrêté sur la signification et l'importance de cette distinction presque toujours sous-jacente à son ceuvre » (p. 63).

La seconde partie porte sur la révolution et évalue le pessimisme et l'optimisme de Marcuse. Il est toutefois regrettable que l'auteur attribue à Marcuse la célèbre phrase de Walter Bemjamin sur laquelle se termine L'bomme unidimensionnel. "C'est seulement à cause de ceux qui sont sans espoir que l'espoir nous est donné. » (p. 113)

La « postface » qui tient lieu de conclusion tente d'établir un rapprochement entre Henri Lefebvre et Marcuse en confondant totalitarisme et terrorisme. Faut-il rappeler ici que Walter Laqueur écrivait dans Le terrorisme (P. U. F., 1979, p. 220) : "cette idéologie (en parlant de Marcuse et de la Nouvelle 
Gauche) n'avait rien à voir avec le terrorisme ». « Le seul avenir du politique, écrit pourtant André Vachet, dans la société technocratique semble être devenu le terrorisme », et il ajoute «c'est ce qui le rend dangereux ».

Dans l'ensemble, l'auteur tente d'expliquer Marcuse par lui-même. Il a réussi à faire un certain nombre de rapprochements de textes qui éclaire de fait la pensée de Marcuse par ses propres textes.

L'ouvrage se termine par une bibliographie qui dans la partie I, Cannonce entre autres les comptes rendus utiles aux prises de position de Marcuse. Pourtant aucun des quelque soixante comptes rendus d'environ cent cinquante volumes faits par Marcuse ne sont mentionnés. La partie II, Best consacrée à l'École de Francfort. Elle comprend six titres. Inutile de dire qu'il faut chercher ailleurs pour être bien renseigné. Dans la partie II, D- il semble bien que tous les mémoires de maîtrise sur Marcuse présentés à l'Université d'Ottawa sont mentionnés.

Département de pbilosopbie

Collège de Granby 